\title{
Conhecimento do consumidor e forma de apresentação da batata no mercado no Estado de São Paulo
}

Consumer knowledge and exposition of potato tubers in the state of São Paulo

\author{
Priscilla Nátaly de Lima Silva ${ }^{1}$; Raineldes Fexina Junior 2; Elcio Ferreira dos Santos ${ }^{3}$
}

\author{
1 Unesp - Doutoranda em Horticultura - R. Dr. José Barbosa de Barros, 1780, CEP 18610-307 - Botucatu \\ (SP), Brasil \\ 2 Itaú Unibanco S.A. - Gerente de Vendas de Recursos Direcionados - Rua Felipe Gonçales, 217 - Casa \\ 2 - Jardim Regente - 13336-322 - Indaiatuba (São Paulo), Brasil \\ 3 CENA/USP - Doutorando em Ciências - Avenida Centenário, 303 - São Dimas, CEP 13400970 - \\ Piracicaba (SP), Brasil
}

\section{Resumo}

A batata é um dos alimentos mais consumidos no mundo e possui alta importância alimentar devido à sua versatilidade e constituição nutricional. Além disso, é um alimento prático e barato, podendo ser consumida de diversas formas, assada, cozida e frita. Apesar de toda essa importância observa-se no Brasil uma grande queda no consumo per capita de batata "in natura". Essa queda pode estar relacionada ao conhecimento equivocado que o consumidor tem sobre a batata. O objetivo do trabalho foi avaliar o conhecimento do consumidor sobre a batata bem como esse produto é ofertado. Foram entrevistadas 215 pessoas e visitados 15 estabelecimentos e verificou-se que muitos consumidores estão cientes das diferenças entre as aptidões das cultivares. Porém, quando questionado quais cultivares conhecia muitos não souberam informar corretamente. Nos estabelecimentos foi verificado que, na maioria, o modo de ofertar batata "in natura" é ultrapassado, não passa informações sobre nome de cultivares e nem sobre a aptidão, confundindo mais ainda o consumidor.

Palavras-chave: aptidão culinária, consumo, in natura, Solanum tuberosum L.

\section{Abstract}

Potato is one of the most consumed foods in the world due to its versatility and nutritional content being particularly important to world food supply. Besides, it is a practical and cheap food and can be consumed in several forms, roasted, baked and fried. In Brazil, there was a considerable reduction in the per capita consumption of potato tubers and the mistaken information that the consumer has about potato might be the reason. The objective of this work was to assess the knowledge that consumers have about potato and how this product is offered. Two hundred fifteen people were interviewed and 15 establishments were visited and, it was found that many consumers are aware of the differences between the adaptability of the varieties. However, when asked which varieties they knew, many did not inform it correctly. It was verified in many establishments that the way of supplying potato tuber is, outdated and not giving information about the name of the variety nor about versatility confuses even more the consumer. Keywords: culinary adaptability, consumption, tubers, Solanum tuberosum $L$.

\section{Introdução}

A batata (Solanum tuberosum L.) é nativa da Cordilheira dos Andes, onde há relatos do cultivo e consumo há mais de oito mil anos. Durante o século XVI a batata foi introduzida na Europa pelos espanhóis e então adaptada para as condições européias tornando-se um alimento muito importante (EMBRAPA, 1999; Filgueira, 2003).

\footnotetext{
${ }^{1}$ Autor correspondente <priscilla_nataly@hotmail.com>

Enviado: 06 abr. 2016

Aprovado: 16 maio 2016
} 
No Brasil, a batata foi introduzida por imigrantes europeus, principalmente por espanhóis e ingleses, por isso ficou conhecida como batata-inglesa, e teve o cultivo mais intenso no início na década de 1920. Hoje é considerada a principal hortaliça do país, tanto em área cultivada como em preferência alimentar (EMBRAPA, 1999).

Em 2014, o Brasil produziu mais de 3,6 milhões de t de batata em uma área de aproximadamente $131 \mathrm{mil}$ ha, acarretando uma produtividade média de $27,5 \mathrm{t} \mathrm{ha}^{-1}$. As principais regiões produtoras são: Sudeste $(53,47 \%)$, Sul $(36,08 \%)$, Centro Oeste $(5,73 \%)$ e Nordeste $(4,72 \%)$ (IBGE, 2014).

A batata possui alta importância alimentar, é um alimento prático, barato, de fácil preparo e versátil, podendo ser consumida cozida, assada e frita, e ainda, tem uma rica constituição nutricional. O teor de proteína varia de 1,2 a 5,0 g por $100 \mathrm{~g}$ de parte comestível, dependendo da maneira de preparo. Teores de potássio variam de 161 a $489 \mathrm{mg}$ por $100 \mathrm{~g}$ de parte comestível. Além de conter cálcio, magnésio, fósforo, ferro e vitaminas tipo C, B1 (Tiamina), B2 (Riboflavina), B3 (Niacina) e B6 (Piridoxina) (NEPA, 2011).

No Brasil, a cultivar de batata mais plantada é a Agata. Estima-se que ela tenha uma participação de mercado de $70 \%$ da produção nacional, seguida em menor quantidade por Cupido, Asterix, Atlantic, Mondial, Markies entre outras (Haddad, 2009).

As cultivares apresentam diferentes qualidades físicas e químicas que irão influenciar na forma do preparo, estas características estão relacionadas à quantidade de matéria seca e ao teor de açúcar. Para elaboração de massas, altos teores de matéria seca propiciam maior rendimento, melhor textura e sabor. Para preparação de frituras, as batatas devem possuir alto teor de matéria seca e baixo teor de açúcares redutores, pois altos teores de açúcares resultam em produto de coloração escura e baixo teor de matéria seca ocasiona maior absorção de óleo durante a fritura (Fernandes et al. 2010).

Apesar da importância nutricional, o consumo de batata in natura no Brasil tem caído ao longo dos anos. De acordo com análises realizadas por Inoue et al.(2010), o consumo de batata in natura que em 1987 era de 13,04 kg hab-1.ano-1. em 1996 reduziu para 9,22 kg, em 2002 caiu para 6,56 kg e em 2008 ficou em 5,6 kg hab-1.ano-1.

Segundo Inoue et al.(2010) em 2008 a média brasileira de aquisição domiciliar per capita anual foi de 4,037 kg. A região Sul ficou acima da média, com aquisição de $7,668 \mathrm{~kg}$, seguida pelas regiões Sudeste $(4,241 \mathrm{~kg})$, Centro-Oeste $(3,001 \mathrm{~kg})$, Nordeste $(2,837 \mathrm{~kg})$ e Norte $(1,579 \mathrm{~kg})$. Em todas as regiões foi detectada redução no consumo de batata entre os anos de 2002 e 2008, exceto na região Nordeste. 
Inoue et al. (2010) também analisaram o consumo em relação à renda familiar. Em famílias com renda de até três salários mínimos, considerada pobre, o consumo de batata foi de $2,74 \mathrm{~kg} \mathrm{hab}^{-1}$.ano-1, já nas famílias de classe média (três a dez salários mínimos) o consumo foi de 4,65 kg hab-1.ano-1 e nas famílias de classe rica (mais de dez salários mínimos) o consumo foi de $5,71 \mathrm{~kg} \mathrm{hab}^{-1}$.ano-1.

Em contrapartida o consumo de batata pré-frita congelada aumentou. Segundo dados divulgados pelas empresas Bem Brasil e McCain publicados por Ramos et al. (2013), o consumo per capita passou de zero em 1997 para 300 g, em 2007 chegou a $700 \mathrm{~g}$ e em 2012 foi de 1,6 kg. De acordo com Cardoso; Silva (2014) pelo segundo ano consecutivo o Brasil registrou volumes recordes de importação de pré-frita congelada, sendo $247 \mathrm{t}, 8,81 \%$ a mais que no acumulado do ano anterior.

Entender as novas necessidades do consumidor e traçar o seu perfil é essencial para definir as novas estratégias, ganhar mercado e atender a demanda. Apesar de a batata ser um alimento muito popular, o consumidor aparenta ser bastante confuso e ter conhecimentos equivocados sobre esse produto. A forma de ofertar o produtor ao cliente precisa ser inovada para continuar a garantir a atração do consumidor.

Este trabalho tem como objetivo avaliar o conhecimento do consumidor sobre a batata in natura e como esse produto é oferecido no mercado.

\section{Material e Métodos}

Para mensurar o conhecimento do consumidor em relação à batata in natura e sobre o hábito do consumidor foi realizada uma pesquisa prévia de mercado com formulários eletrônicos elaborados através do GoogleForms e enviado na rede social (facebook) durante todo o mês de julho de 2015.

O formulário abordou questões sobre faixa etária e sexo da pessoa responsável por fazer as compras de alimentos na família, forma de consumo de batata in natura e batata congelada, modo de preparo mais utilizado, conhecimento prévio sobre cultivar de batata, e se afirmativo, quais são, conhecimento da existência de diferenças entre as cultivares e importância em conhecer o nome da cultivar e sua aptidão na hora da compra.

A segunda etapa deste trabalho foi constatar como a batata in natura é apresentada nos mercados. Foram visitados 15 estabelecimentos, sendo um localizado na cidade de Vargem Grande do Sul, dois em Campinas, oito em Indaiatuba e quatro em São Paulo, todas as cidades do Estado de São Paulo. 


\section{Resultados e Discussão}

A pesquisa de mercado foi respondida por 215 pessoas durante o mês de julho de 2015. Foi questionado qual a faixa etária da pessoa geralmente responsável por realizar as compras de alimentos, houve a prevalência de pessoas entre 31 a 60 anos de idade (Figura 1).

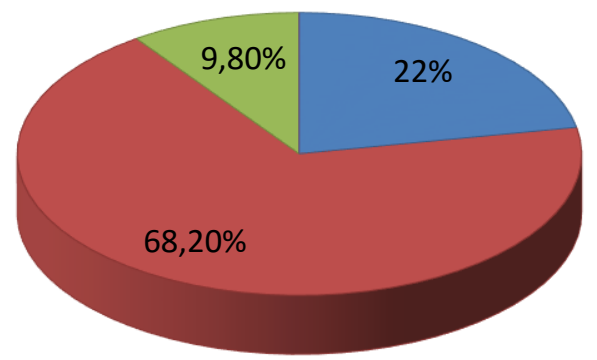

$\square$ Até 30 anos

$\square$ Entre 31 a 60 anos

$\square$ Acima de 61 anos

Figura 1. Faixa etária dos entrevistados

Quanto ao sexo de quem realiza as compras de alimentos, verificou-se que $55,1 \%$ dos entrevistados responderam que o sexo feminino é responsável pelas compras em casa.

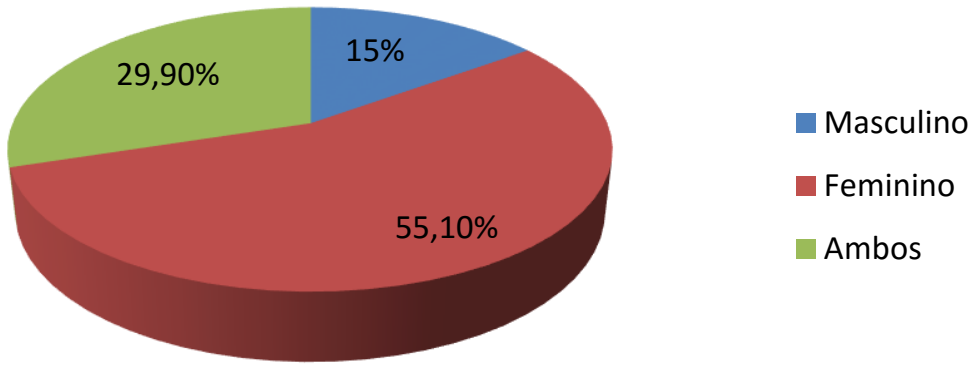

Figura 2. Sexo dos entrevistados

Foi questionado aos entrevistados sobre o hábito de consumir batata in natura e $89,7 \%$ deles afirmaram que possuem o hábito de consumo, demonstrando que este é um alimento importante e lembrado pelo consumidor. A Figura 3, relaciona a quantidade média mensal consumida informada pelos entrevistados e a maioria dos entrevistados $(56,82 \%)$ afirmaram consumir até $3 \mathrm{~kg}$ de batata mensalmente. 


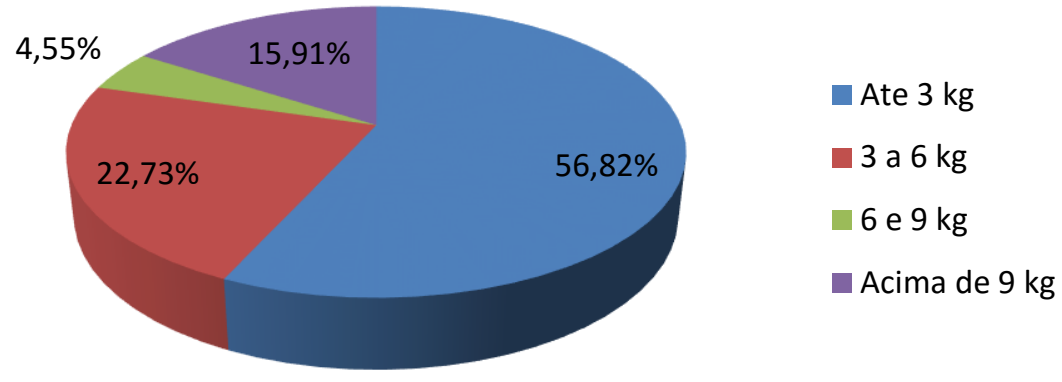

Figura 3. Quantidade mensal de batata in natura consumida pelos entrevistados

Quando questionado se os entrevistados tinham o hábito de adquirir batata congelada, 63,7\% afirmaram que sim. Esse dado mostra que o estilo de vida do brasileiro tem passado por mudanças, o aumento do poder aquisitivo e a participação maior da mulher no mercado de trabalho estão impulsionando mudança nos hábitos alimentares do brasileiro e o consumidor tem buscado mais praticidade, preferindo alimentos processados e fáceis de preparar. A maioria dos entrevistados $(82,05 \%)$ afirmaram consumir até $2 \mathrm{~kg}$ de batata congelada por mês (Figura 4).

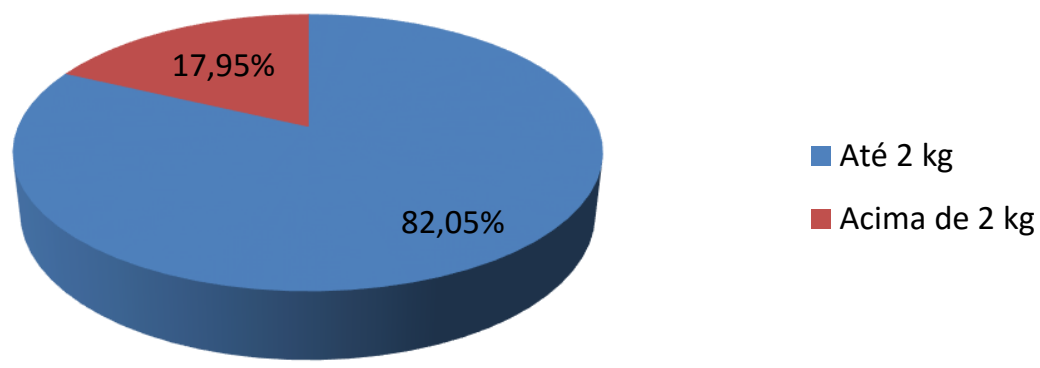

Figura 4. Quantidade mensal de batata congelada consumida pelos entrevistados

Para entender de que forma o consumidor prefere utilizar as batatas, questionouse quanto ao modo de preparo mais utilizado (Figura 5). Foi interessante observar que mesmo os dados mostrando que a importação de batata processada tem aumentado (Cardoso; Silva 2014), o modo de preparo frito foi o menos citado como preferência do consumidor, demonstrando que o brasileiro está cuidando melhor de sua saúde. 


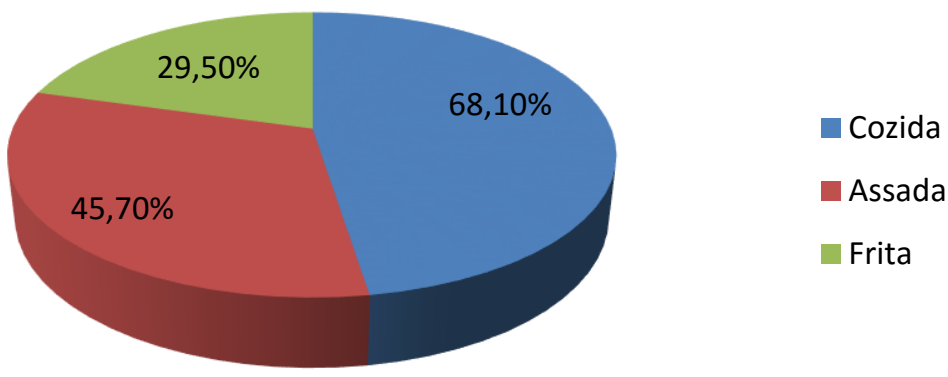

Figura 5. Modo de preparo da batata mais utilizado pelos entrevistados

O maior foco deste trabalho foi verificar o conhecimento do consumidor sobre o produto, por isso quando os entrevistados foram questionados se eles conheciam a existência de cultivares especificas para cada modo de preparo, ou seja, a aptidão culinária da cultivar, 71,2\% afirmaram saber desta informação. No entanto, ao questionar se os participantes conheciam alguma cultivar, $43 \%$ participantes afirmaram conhecer alguma cultivar, porém destes, $30 \%$ participantes cometeram enganos quanto aos nomes das cultivares de batata, ou seja, os entrevistados sabem da existência de diferentes cultivares, mas não sabem identificar. Isso demonstra que o entendimento do consumidor sobre o produto é confuso e equivocado, é um mercado que precisa ser explorado de forma correta, em harmonia com os novos perfis de consumidor e, assim, aumentar o consumo deste importante produto.

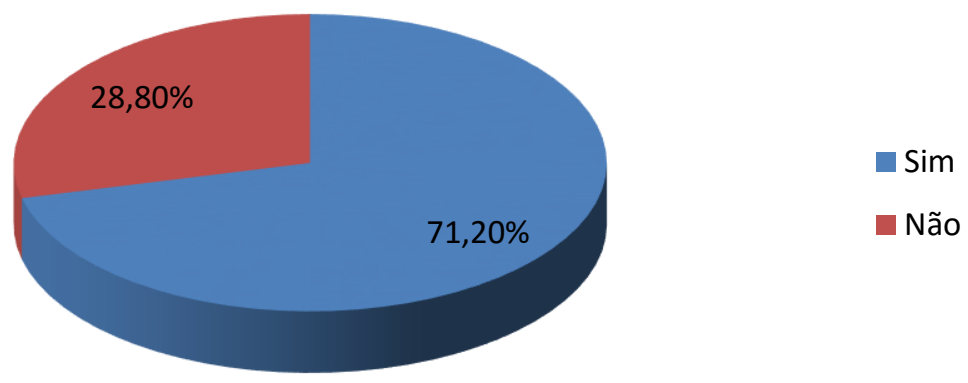

Figura 6. Conhecimento dos consumidores sobre cultivar de batata correta para cada modo de preparo

Entre os entrevistados, 81\% afirmaram a importância de saber o nome da cultivar da batata no ato da compra (Figura 7). 


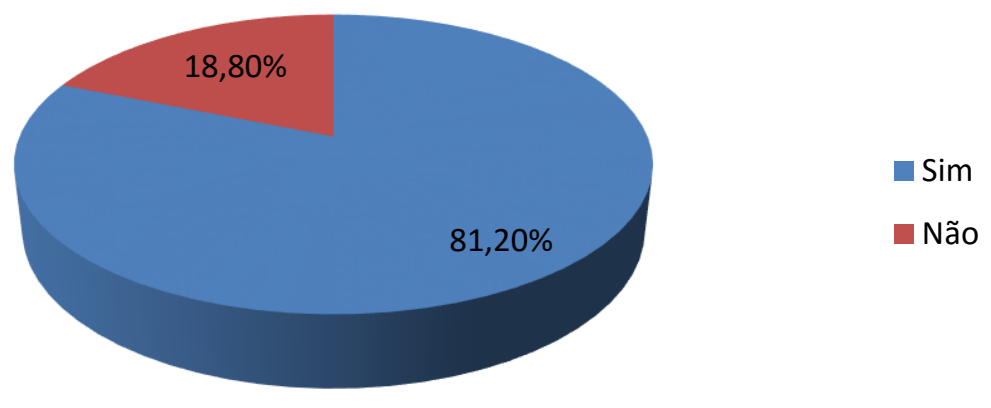

Figura 7. Importância de ser informado sobre o nome da cultivar da batata no momento da compra

Questionou-se também sobre a importância em conhecer a aptidão ou modo de preparo mais adequado para a cultivar que estava adquirindo e $90,4 \%$ concordaram.

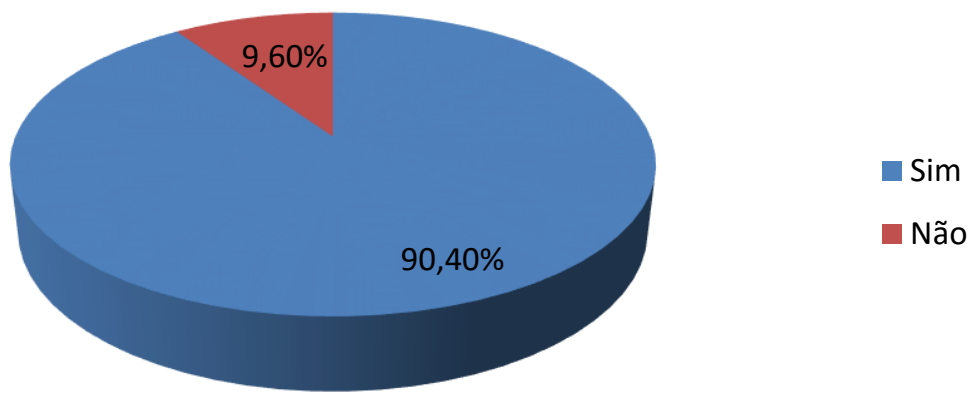

Figura 8. Relevância em ser informado sobre a aptidão culinária da cultivar da batata no momento da compra

O consumidor mais informado com o que está adquirindo, faria melhor uso do produto, ficaria mais satisfeito com os resultados e, possivelmente, alavancaria 0 consumo de batata no Brasil.

Uma forma mais elaborada de passar essas informações ao consumidor seria a possibilidade de a batata vir agrupada em embalagens de $1 \mathrm{~kg}$ e as informações como nome da cultivar e aptidão culinária poderiam vir impressos no rótulo. A embalagem ajudaria ainda a agregar valor ao produto e poderia trazer mais segurança alimentar, apresentando selos e certificados de qualidade.

Outra ação que poderia ocorrer de forma mais simples e imediata, seria se as informações sobre nome de cultivar e aptidão culinária viessem contidas nas gôndolas dos supermercados. 


\section{Análise de como o produto é ofertado}

Para verificar como a batata está sendo ofertada ao consumidor final, foram feitas visitas a 15 estabelecimentos (pequenos e grandes supermercados).

Em nove estabelecimentos as batatas eram nomeadas como "batata comum", "batata extra", "batata a granel" ou simplesmente "batata", não trazendo nenhuma informação mais específica sobre o produto e forma de uso.

Houve um estabelecimento que utilizou um nome de cultivar inexistente, trazendo na gôndola o nome "Binge rosada". Bintje é uma cultivar muito antiga, que é produzida em escala reduzida no Brasil (Santos, 2014).

Essa cultivar possui pele amarela, porém, neste estabelecimento usou-se para nomear a cultivar de pele rosada, que provavelmente seria a cultivar Asterix.

Ribeiro et al. (2011) destacam a necessidade da certificação correta das cultivares de batata de maneira a assegurar a qualidade e a regularidade de informações verdadeiras ao cliente, sugerindo a criação de um selo, pois, a maioria das cultivares de batata são fisicamente muito semelhantes e o consumidor pode ser facilmente enganado.

Em outros três estabelecimentos, foi possível encontrar duas cultivares de batata. Em uma gôndola estavam as batatas de pele amarela que tinham nomenclatura comum "batata". Porém, havia em outra gôndola batatas com pele roxa nomeadas "Asterix". Além disso, em dois destes estabelecimentos, pertencentes a mesma rede de supermercado, considerada de alto padrão, havia opções de batatas embaladas em sacos de malha com informações sobre a aptidão na embalagem.

Este estudo mostra que o consumidor aprecia o produto, porém, tem informações equivocadas sobre ele. Além de demonstrar que gostaria de obter mais informações, saber que tipo de produto está adquirindo e qual o melhor modo de preparo deste produto.

luamoto (2005) afirma que o consumidor passou a buscar comodidade e praticidade trocando as feiras livres por grandes mercados onde podem encontrar quantidade maior de produtos que necessitam e economizam tempo. Porém, nas gôndolas do supermercado os consumidores estão acostumados a adquirir o produto somente pela aparência e não encontram lá informações sobre o produto que estão adquirindo, especificando somente como "batata" e não indicando a cultivar.

A falta de conhecimento do produto aliado com o modo em que o produto é apresentado no comércio são fatores que podem influenciar na perda de posicionamento da batata in natura no mercado. Por exemplo, o consumidor que compra 
batata para fritar e ao comprar a cultivar inadequada para esse preparo, vai obter batatas queimadas e encharcadas de óleo, pois não encontrou a informação adequada para o melhor modo de preparo.

Além destes, existem também outros problemas específicos que limitam o consumo brasileiro de batata que devem ser levados em consideração, são problemas mais enraizados e difíceis de serem combatidos. Sendo que a questão cultural é um deles, pois a batata não é um alimento básico para a população brasileira, como ocorre em países europeus, norte-americanos e muitos países latino-americanos. O consumo per capita anual na Europa é de $91,4 \mathrm{~kg} \mathrm{hab}{ }^{-1}$.ano-1 e é bem diferente do padrão de consumo brasileiro (Shimoyama, 2011). Outro fator é a questão econômica, porque no Brasil a proteína animal é barata e compete diretamente com o consumo de batata (Albuquerque, 2008).

\section{Conclusão}

A maioria dos consumidores tem conhecimento sobre a batata in natura e a existência de cultivares específicas para cada modo de preparo.

Os consumidores desejam saber o nome da cultivar no ato da compra e sua aptidão culinária.

O modo de ofertar o produto demonstra estar ultrapassado e inadequado ao utilizar nome errado das cultivares e não especificar seu modo de preparo.

\section{Referências}

Albuquerque, C. 2008. Ano Internacional da Batata. Disponível em: <http://www.abhorticultura.com.br/News/?id=6357>. Acesso em: 25 mar. 2015.

Cardoso, F.; Silva, A.R. 2014.Preços são recordes no primeiro trimestre, mas despencam no segundo. Anuário 2014-2015. Revista Hortifruti Brasil 141: 18-20.

Empresa Brasileira de Pesquisa Agropecuária [EMBRAPA]. 1999. Coleção Plantar Batata: A cultura da batata. Embrapa Informação Tecnológica, Brasília, Distrito Federal, Brasil.

Fernandes, A.M.; Soratto, R.P.; Evangelista, R.M.; Nardin, I. 2010. Qualidade físicoquímica e de fritura de tubérculos de cultivares de batata na safra de inverno. Horticultura Brasileira 28: 299-304.

Filgueira, F.A.R. 2003. Solanáceas: Agrotecnologia moderna na produção de tomate, batata, pimentão, pimenta, berinjela e jiló. Universidade Federal de Lavras, Lavras, Minas Gerais, Brasil.

Haddad, A. 2009. Preço batata consumo. Revista Batata Show 24:4. 
Instituto Brasileiro de Geografia e Estatística [IBGE]. 2014. Levantamento sistemático da produção agrícola. Disponível em:

<ftp://ftp.ibge.gov.br/Producao_Agricola/Levantamento_Sistematico_da_Producao_Agr icola_\%5Bmensal\%5D/Fasciculo/2014/lspa_201412.pdf >. Acesso em: 12 maio 2016.

Inoue, K.; Silveira, M.S.; Viana, M.M. 2010. Desafios e oportunidades de agregar valor na cadeia de hortifrutis. Revista Hortifruti Brasil 92: 8-19.

Iuamoto, M.Y. 2005. Comercialização de batata na CEAGESP. Revista Batata Show, 13: 34-35.

Núcleo de Estudos e pesquisas em Alimentação [NEPA]. 2011. Tabela Brasileira de Composição de Alimentos (TACO). p.30-31. Unicamp, Campinas, São Paulo, Brasil.

Ramos, R. M.; Silva, A. R. da; Dumbra, J. G. R. 2013. O aquecido mercado dos vegetais congelados. Revista Hortifruti Brasil 122: 8-21.

Ribeiro, R.C.; Sant'ana, H.M.P.; Pádua, J.G.; Chaves, J.B.P. 2011. Fatores que influenciam a compra e uso de batatas e repercussões na oferta de cultivares francesas no município de Belo Horizonte. In: IV Congresso Mineiro de Alimentação e Nutrição e I Congresso Nacional de Alimentos e Nutrição, Ouro Preto. Anais do V Congresso Mineiro de Alimentação e Nutrição e I Congresso Nacional de Alimentos e Nutrição. p.533-539.

Santos, C.J. 2014. A batata nunca foi inglesa! Ela sempre foi Peruana, Boliviana e Chilena. Revista Batata Show 38: 4.

Shimoyama, N. 2011. Batata é ótima opção para acabar com a fome no mundo. p. 181-182. In: Anuário da Agricultura Brasileira [AGRIANUAL]. IFNP, São Paulo, São Paulo, Brasil. 